\title{
Anterior Urethral Valve- Rare cause of Urethral Obstruction- A case Report
}

\author{
Patel $\mathbf{U}^{1}$, Grower $\mathbf{J}^{2}$, Ali $\mathbf{Q}^{3}$, Sinde $\mathrm{S}^{4}$, Patel $\mathrm{VK}^{5}$ \\ ${ }^{1}$ Dr. Umesh Patel, Associate Professor (Pediatrics), ${ }^{2}$ Dr. Jitendra Grower, Assistant Professor (Pediatric Surgery), ${ }^{3}$ Dr. Qutub \\ Ali, Assistant Professor (Urology), ${ }^{4}$ Dr. Seema Sinde, Assistant Professor (Anesthesiology). All are affiliated to LN Medical \\ College, Bhopal (MP), ${ }^{5}$ Dr. Vishnu Kumar Patel, Assistant Professor (Surgery), S S Medical College, Rewa (MP), India
}

Address of Corresponds: Dr. Umesh Patel, Email: drumeshpatel@gmail.com

\begin{abstract}
Anterior urethral valve (AUV) is extremely rare entities. It is an uncommon cause of lower urinary tract obstruction in children and can be difficult to diagnose. The symptoms mimic those of posterior urethral valves. Because of rarity, less common presentations in children and lack of awareness among the pediatrician and pediatric surgeons, it can be easily missed.
\end{abstract}

Key words: Anterior urethral valve, Urinary tract obstruction, Posterior urethral valve

\section{Introduction}

Anterior urethral valves were first described by Watts in 1906 as a cause of urethral obstruction [1]. Since then, very few cases have been reported in medical literature. Anterior urethral valves (AUV) are extremely rare congenital condition, which cause lower urinary tract obstruction in male children and may be difficult to diagnose. It can occur as an isolated entity or in association with the proximal diverticulum. The frequency of AUV is eight times lower than the frequency of posterior urethral valve (PUV) [2]. It can cause more sever obstruction than PUV [3]. Depending on the age of the patient and the severity of obstruction, clinical presentation highly varies from a stream that dribbles and voids poorly to hydroureteronephrosis and end-stage renal disease. Children with poor stream and recurrent urinary tract infections should be evaluated carefully and AUV or diverticula should be considered in differential diagnosis of obstructive lesions [4]. Improved imaging modalities including ultrasound and VCUG and cystoscopy, have resulted in early and accurate detection and treatment. AUV may be associated with other congenital anomalies of the renal system. We are reporting a case of a four years old child with AUV who presented with features of bladder outlet obstruction.

\section{Case Report}

Manuscript received: $5^{\text {th }}$ Oct 2014

Reviewed: $16^{\text {th }}$ Oct 2014

Author Corrected; $19^{\text {th }}$ Oct 2014

Accepted for Publication: $5^{\text {th }}$ Nov 2014
A four years old boy presented with two years history of difficulty in passing urine, poor urinary stream and dribbling of urine. Examination revealed under developed physical growth, normal looking male external genitalia, normal size urethral opening and no phimosis. No bladder was palpable in the suprapubic area. Urine analysis was normal but renal functions was abnormal with blood urea $120 \mathrm{mg} \%$ and serum creatinine $2.1 \mathrm{mg} \%$. Renal ultrasound showed normal kidney and ureter and mild bladder muscle hypertrophy. VCUG revealed thickening of bladder wall with trabeculations and dilated urethra in its entire length with obstruction at the distal end of penile urethra. Cystoscopy revealed typical fibrous cusp like valves in anterior urethra, proximal to navicular fossa. Endoscopic fulguration was done successfully. There was complete resolution of symptoms and normalization of renal function on follow-up.

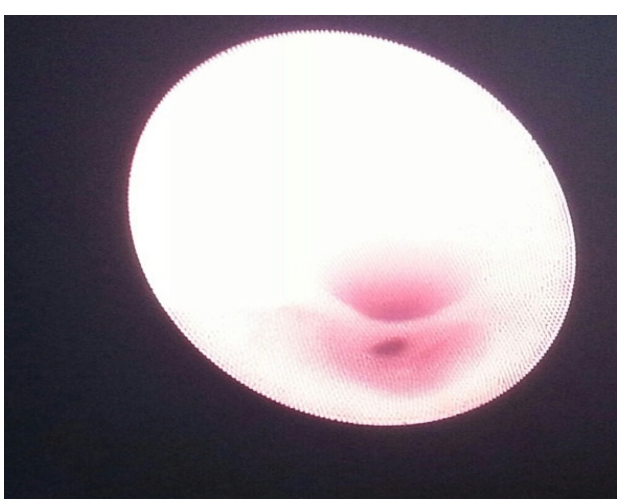

Fig 1: Anterior urethral valve

Available online at: $\underline{w w w . p e d i a t r i c r e v i e w . i n}$

58 | P a g e 


\section{Discussion}

Anterior urethral valves (AUV) are a rare cause of urinary obstruction in male children. Posterior urethral valves, ureterocele, bladder stone, bladder diverticulae and meatal stenosis are other more common cause of urinary obstruction. AUV is a congenital mucosal fold located distally to the membranous urethra. The sites of an AUV can be bulbar urethra (40\%), penoscrotal junction (30\%), pendulous urethra $(30 \%)$, and occasionally in the fossa navicularis [5]. The embryological origin of AUV remains uncertain. There is various proposed etiological theories include an abortive attempt at urethral duplication, failure of alignment between the proximal and distal urethra, imbalanced tissue growth in the developing urethra resulting in excessive tissue remnant acting as a valve and congenital cystic dilation of periurethral glands, resulting in a flap-like valve [10].

Time of presentation depending on the severity of the anatomical obstruction, it may present antenatally, soon after birth or later in childhood. The clinical presentation of anterior urethral valves is similar to that of PUV. Symptoms may ranges from mild urethral dilatation to bilateral hydronephrosis with renal insufficiency (in $<5 \%$ cases) in severe cases. In developed countries, because of routine antenatal screening, it is diagnosed as antenatal hydronephrosis, but in developing countries like India, presentation is usually delay and children usually comes with obstructive symptoms and urinary tract infection. Patients with significant upper tract deterioration present at a younger age [7]. Urethral diverticulum may be present with AUV and in these cases a swelling appears during voiding. This has to be differentiated from congenital megalourethra where there is loss of supporting tissue around the urethra and dilation is nonobstructive.

Ultrasonography will suggest features of bladder outlet obstruction but antegrade VCUG is the investigation of choice for the evaluation of AUV, as any attempt of urethral catheterization may disrupt the pathology, and the exact diagnosis can be missed. In VCUG, the urethra appears dilated proximal to the valve and narrow distal to it. If no abnormality is detected on antegrade VCUG, then only a retrograde urethrogram should be performed. Cystoscopy is necessary for full evaluation of the urethra and nature of valves. Cystourethroscopy may show cusplike valves in the anterior urethra, although it is less accurate because retrograde flow induces the valve to lie flat against the urethral wall. In severe obstruction, early diagnosis has advantage, as complication of obstruction like hydronephrosis, hydroureter, renal dysfunction can be preventaed. Thus, the routine use of prenatal ultrasonography will probably alter the mode of presentation and clinical outcomes $[6,7]$.

Initial management of a congenital AUV is the same as that for the PUV. Cystoscopic valve ablation may be achieved using electro-resection or laser ablasion, if the urethra is of sufficient caliber [8,9]. Open urethroplasty is useful in patients with a large urethral diverticulum and thin urethra. If facilities for endoscopic ablation are not available, open valve resection is equally good.

It has been seen, that patients with congenital anterior urethral obstruction have a better prognosis than those with PUV, has less chance of hydronephrosis, and a lower incidence of chronic renal insufficiency (5 vs. 30\%). The long-term prognosis of AUVs is not clear in the literature.

\section{Conclusion}

Children with poor stream and recurrent infections should be evaluated carefully for congenital obstructive malformation and anterior urethral valves should be considered in differential diagnosis of obstructive lesions.

\section{Funding: Nil \\ Conflict of interest: Nil \\ Permission from IRB: Yes}

\section{References}

1. McLellan DL, Gaston MV, Diamond DA, Lebowitz RL, Mandell J, Atala A, et al. Anterior urethral valves and diverticula in children: a result of ruptured Cowper's duct cyst? BJU Int. 2004;94:375-378

2. Xiaomei L, Yajuan W, Fang S, Dan W. Sepsis in a newborn with anterior urethral valve and urinary tract infection. Chinese Medical Journal 2014;127(2):399-400.

3. Kajbafzadeh A. Congenital urethral anomalies in boys. Part II. Urol J.2005 Summer;2(3):125-31.

4. Kibar Y, Coban H, Irkilata HC, Erdemir F, Seckin B, Dayanc M. Anterior urethral valves: An uncommon cause of obstructive uropathy in children. J Pediatr Urol. 2007 Oct; 3(5): 350-3.

5. Zia-ul-Miraj M. Anterior urethral valves: a rare cause of infravesical obstruction in children. J Pediatr Surg. 2000 Apr;35(4):556-8.

6. Rushton HG, Parrott TS, Woodard JR, Walther M. The role of vesicostomy in the management of anterior urethral valves in neonates and infants. $\mathrm{J}$ Urol. 1987;138:107-109.

Available online at: www.pediatricreview in

59 | P a g e 
7. Van Savage JG, Khoury AE, McLorie GA, Bagli DJ. An algorithm for the management of anterior urethral valves. J Urol. 1997;158(3 Pt 2):1030-1032.

8. Mali VP, Prabhakaran K, Loh DS. Anterior urethral valves. Asian J Surg 2006;29(3):165-9.
9. Al-Busaidy SS, Prem AR, Medhat M, Al-Bulushi YH. Holmium laser ablation of anterior urethral valves: case report. J Endourol 2005;9:1210-11.

10. Rawat J, Khan TR, Singh S, Maletha M, Kureel S. Congenital anterior urethral valves and diverticula: Diagnosis and management in six cases. Afr J Paediatr Surg. 2009;6:102-5.

\section{How to cite this article?}

Patel U, Grower J, Ali Q, Sinde S, Patel VK. Anterior Urethral Valve- Rare cause of Urethral Obstruction- A case Report . Pediatr Rev: Int J Pediatr Res 2014;1(2):58-60. doi:10.17511/ijpr.2014.i02.04 